\title{
Crystal fractionation-induced magnesium isotope fractionation in basalts from Mauna Kea, Hawaii
}

\author{
Christopher DeFELICE ${ }^{1 *}$, YAN HU ${ }^{2}$, WENZHONG \\ WANG $^{3}$, FANG-ZHEN TENG $^{2}$, SHICHUN HUANG ${ }^{1}$, \\ FREDERICK A. FREY ${ }^{4}$ \\ ${ }^{1}$ Depatment of Geoscience, University of Nevada, Las Vegas \\ ${ }^{2}$ Department of Earth and Space Science, University of \\ Washington, Seattle, WA \\ ${ }^{3}$ University of College London, UK \\ ${ }^{4}$ Massachusetts Institute of Technology, Cambridge, MA \\ *Corresponding author: defelc1@unlv.nevada.edu
}

Fractionations of metal stable isotopes are controlled by both temperature and differences in bonding enviornments. Magnesium isotopic compositions of tholeiitic ocean island basalts are generally homogeneous and indistinguishable from that of the mantle $\left(\delta^{26 / 24} \mathrm{Mg}=-0.25 \pm 0.04 \%\right.$ ). These initial observations led to the conclusion that fractional crystallization of silicate minerals does not fractionate $\mathrm{Mg}$ isotopes. However, analyses of alkalic basalts from Mauna Kea volcano, Hawaii have shown that their $\delta^{26} \mathrm{Mg}$ varies to values both heavier and lighter (-0.10 to $-0.40 \%$ ) than typical mantle values. These alkalic basalts are more evolved and have frationated oxide mineral phases other than olivine, such as ilmenite and magnetite. There is no correlation between $\delta^{26} \mathrm{Mg}$ and tracers of source heterogeneity, such as ${ }^{87} \mathrm{Sr} /{ }^{86} \mathrm{Sr}$. If the observed variation in $\delta^{26} \mathrm{Mg}$ cannot be attributed to source heterogeniety, we hypothesize magmatic processes as a potential source of fractionation. Differences in $\mathrm{Mg}-\mathrm{O}$ bonding environments between Fe-Ti oxides and silicates are a potential source of variability in measured samples. To understand the observed $\delta^{26} \mathrm{Mg}$ variation in alkalic basalts, we model the fractional crystallization history of these alkalic basalts using MELTS software. Together with inter-mineral $\mathrm{Mg}$ isotope fractionation factors obtained from $a b$ initio calculations, we explore different crystal fractionation models to explain both major element and metal isotopic variation in Mauna Kea post-shield lavas for a more complete understanding of the crystallization history of these samples. 